\title{
Evidence of clinical competence by simulation, a hermeneutical observational study
}

\section{Lejonqvist, Gun-Britt}

2016-03

Lejonqvist, G-B , Eriksson, K \& Meretoja , R 2016 , ' Evidence of clinical competence by simulation, a hermeneutical observational study ', Nurse Education Today, vol. 38 , pp. 88-92 . https://doi.org/10.1016/j.nedt.2015.12.011

http://hdl.handle.net/10138/223912

https://doi.org/10.1016/j.nedt.2015.12.011

publishedVersion

Downloaded from Helda, University of Helsinki institutional repository.

This is an electronic reprint of the original article.

This reprint may differ from the original in pagination and typographic detail.

Please cite the original version. 


\title{
Evidence of clinical competence by simulation, a hermeneutical observational study
}

\author{
Gun-Britt Lejonqvist ${ }^{\mathrm{a}, *}$, Katie Eriksson ${ }^{\mathrm{b}, 1}$, Riitta Meretoja ${ }^{\mathrm{c}, 2}$ \\ a Arcada University of Applied Sciences, Jan-Magnus Janssons plats 1, 00550 Helsinki, Finland \\ b Caring Science, Åbo Akademi University, Strandgatan 2, PB 311, 65101 Vasa, Finland \\ c Corporate Headquarters, Helsinki University Hospital, HUS, PL 100, 00029, Finland
}

\section{A R T I C L E I N F O}

\section{Article history:}

Accepted 14 December 2015

\section{Keywords:}

Clinical competence

Evidence

Hermeneutics

Nursing education

Observation

Simulation

\begin{abstract}
S U M M A R Y
Making the transition from theory to practise easier in nursing education through simulation is widely implemented all over the world, and there is research evidence of the positive effects of simulation. The preunderstanding for this study is based on a definition of clinical competence as encountering, knowing, performing, maturing and developing, and the hypothesis is that these categories should appear in simulated situations. The aim of the study was to explore the forms and expressions of clinical competence in simulated situations and furthermore to explore if and how clinical competence could be developed by simulation. An observational hermeneutic study with a hypothetic-deductive approach was used in 18 simulated situations with 39 bachelor degree nursing students. In the situations, the scenarios, the actors and the plots were described. The story told was "the way from suffering to health" in which three main plots emerged. The first was, doing as performing and knowing, which took the shape of knowing what to do, acting responsibly, using evidence and equipment, appearing confident and feeling comfortable, and sharing work and information with others. The second was, being as encountering the patient, which took the shape of being there for him/her and confirming by listening and answering. The third plot was becoming as maturing and developing which took the shape of learning in co-operation with other students. All the deductive categories, shapes and expressions appeared as dialectic patterns having their negative counterparts.

The study showed that clinical competence can be made evident and developed by simulation and that the challenge is in encountering the patient and his/her suffering.
\end{abstract}

(c) 2015 Elsevier Ltd. All rights reserved.

\section{Introduction}

In nursing education there is an ongoing transition from traditional teaching and learning to more self-directed learning due to the development of the Internet, learning platforms and new technology. Using high-fidelity simulators offers students effective, holistic and active learning (Cook et al. 2013, Schmidt et al. 2011, Murphy et al. 2011), and enables them to experience a variety of realistic situations in safe environments without jeopardizing patient safety. Simulation has become a way to enhance and consolidate learning, since it allows multiple learning objectives to be achieved simultaneously (Yeun et al.2014), and it has a clear impact on students' clinical competence (Gordon et al. 2009, Ironside et al. 2009, Gallo et al. 2014). The traditional teacher role changes to that of a facilitator who provides the students with the

\footnotetext{
* Corresponding author. Tel.: + 358407200708.

E-mail addresses: gun-britt.lejonqvist@arcada.fi (G.-B. Lejonqvist)

katie.eriksson@abo.fi (K. Eriksson), riitta.meretoja@hus.fi (R. Meretoja).

1 Tel.: + 358400360721 .

2 Tel.: + 358503265192
}

possibilities to learn. Since recent studies show that there is no single teaching method that secures clinical competence and safe practise (Cook et al., 2013, White et al. 2013), there is a need to find valid methods to evaluate simulation and its effect on clinical competence and how it transfers to practise.

The Patient Safety Strategy (WHO 2004) together with the complex and demanding nursing reality has brought simulation to nursing education. This article continues the ongoing discussion about the use of simulation to enhance clinical competence and presents one hermeneutical observation study of second-year bachelor degree nursing students in one university of applied sciences in Finland which is engaged in simulation training.

\section{Background}

\section{Simulation Developing and Providing Evidence of Clinical Competence}

Simulation is rooted in Aristotle and Socrates and in experiential learning (Lyons 2012). Mechanical dummies, and models for arms and legs have been used to train and demonstrate clinical competence, and previously role play, case studies and using study mates as patients 
in clinical scenarios were common. Computer-assisted simulation was introduced in the 1980s (Nehring \& Lashley 2009, Khalaila 2014), and its benefits in teaching and in learning important nursing skills are widely recognised (Solnick \& Weiss 2007, Cant \& Cooper 2010, Stanford 2010, Yuan et al. 2011, Rochester et al., 2012, Skrable \& Fitzsimons 2014). Simulation requires a paradigm shift from teaching to learning, stressing teamwork and co-operation. The shift from passive, receptive and content-driven learning to dynamic, active and reflective learning affects identity construction and professionalism (Berragan 2011).

Simulation or scenario learning combines acting and real life. Simulation has the features of a play, as it follows a script; there is a cast, different roles and even costumes, and the performances in the scenarios are referred to in a dramaturgical language (Taylor 2014). At the same time, simulation brings real life into realistic learning environments, by offering authentic learning experiences and by providing possibilities for the students to reflect upon and develop their clinical competence (Hinchcliffe, 2014). Defining the objectives and the stages of the learning process is reminiscent of the action-based learning cycle of Kolb (Kolb \& Kolb 2005), where reflection follows every stage of learning, as every simulation is followed by a debriefing (Levett-Jones \& Lapkin 2014).

Simulation offers safe training of skills, problem solving, critical thinking, decision making, communication, and group- and teamwork (Robinson-Smith et al. 2009, Burns et al. 2010, Alfes 2011, Garrett et al. 2011). The emotional aspect of encountering patients and the affective component of learning are still hard to achieve (McCaughey \& Traynor 2010, Berragan 2011, McGarry et al. 2014), but considering these limitations, simulation can be used as a substitute for clinical work practise placements by offering students equal possibilities to learn (Khalaila 2014). Training in safe environments develops self-confidence, decreases anxiety when encountering real patients, enhances competence and makes students better prepared for clinical practise (McCallum 2007, Gordon \& Buckley 2009, Roberts et al. 2009, Kameg et al. 2010, Yuan et al. 2011, Jensen 2012, McGarth et al. 2012, Reid-Searl et al. 2012, Thomas \& Mackey 2012). Simulation can be used in nursing education at all levels, e.g. by varying the aims so more advanced students can develop prioritising and delegating skills, whilst beginners can concentrate on simple scenarios (Kaplan \& Ura 2010, Pearson \& McLafferty 2011, Tosterud et al. 2013).

\section{Evidence of Clinical Competence}

A recent concept analysis of nursing competence by Smith (2012) shows what is needed when entering nursing practise, and the results are highly relevant for definitions of clinical competence. Smith summarises nursing competence as motivation, including integrating knowledge into practise, experience, critical thinking skills, caring, communication, supportive environment and professionalism including confidence, safe practise and holistic care. Clinical competence is similarly defined as the application of skills in all domains of the practise role, a combination of knowledge, and skills and attitudes basic for emotionally intelligent nursing, which grow and deepen with experience from different contexts (Meretoja et al. 2004, Tilley 2008, Cassidy 2009). In these contexts, clinical competence needs to be demonstrated and made visible. The competence needs to become evident, which means it becomes clear, obvious and indisputable (Scott \& McSherry 2008, Eriksson 2010). In being evident, students combine scientific knowledge and skills based on values and caring ethics (Avis \& Freshwater 2006).

Evidence implies students' seeing and understanding what the patient needs, knowing how to meet those needs, expressing and performing, and when required revising their actions (Eriksson 2010).

\section{The Study}

Aim

In an earlier empirical inductive study which asked third-year bachelor nursing students $(n=21)$, preceptors $(n=21)$ and nursing teachers $(n=9)$ to define clinical competence, the responses revealed that in practise such competence comprises encountering, knowing, performing, maturing and developing/improving. Competence could be seen both as a stage and as an ongoing process, comprising an ontological (general) and contextual dimension (Lejonqvist et al. 2011).

From this pre-understanding, and viewing each simulated situation as a play, the aim of this study was to explore the forms and expressions of clinical competence in contextual simulated situations, and furthermore to find out how clinical competence could be developed by simulation.

The study posed the following questions:

-How are encountering, knowing, performing, maturing and developing shaped and made evident in simulated situations?

-Can clinical competence be facilitated by simulation?

Design

An observational hermeneutic study was used, inspired by Gadamer (1996), with a hypothetico-deductive approach. In this study, the method was used with meaningful material and actions (Føllesdal 1994). The pre-understanding - viewing clinical competence as encountering, knowing, performing, maturing and developing - is based on earlier empirical research (Lejonqvist et al. 2011) and formed the deductive categories for the analyses. Understanding proceeded hypotheticodeductively. Understanding is based on rational assumptions or quoting Gadamer; "agreement is the basis for understanding" (1996). Simulation learning and performing have many parallels (Taylor 2014), the situations were viewed as scenarios/plays, which allowed the researcher to look at them from outside in, as watching a theatre play. The play was allowed to absorb the researcher so it was apprehended as reality. Neither the actors nor the observer existed, only what was played out, the meaning. Through deduction, the evidence (what was known) became visible. (Gadamer 1996, Eriksson et al. 2010). The situations were video-taped and could be watched again and again until everything was unfolded, or quoting Ödman (1979) "the interpreted had been given a meaning".

\section{Sample and Data Collection}

The sample comprised all 47 second year bachelor degree nursing students from a university of applied sciences in Helsinki. The students had previously been in simulation to demonstrate their basic clinical competence. They were now preparing for medical and surgical practise. For the simulation, the students were divided into four groups and the time span was 4 days, each group participating for 1 day. Three students were absent and two of the recordings failed $(n=39)$. The situations were videotaped with the equipment normally used in the simulation centre. The recorded situations numbered 18 over 4 days in February 2012, lasting a total of $4 \mathrm{~h}$ and $25 \mathrm{~min}$. The students entered the stage in pairs ( 10 times) and 3 at a time ( 8 times). Each situation lasted for 10-19 $\mathrm{min}$, on average $15 \mathrm{~min}$, and the situations were all stopped by the two teachers responsible for the simulation. The debriefing sessions after each situation lasted an average of $20 \mathrm{~min}$, but these sessions were not part of the analysed material.

\section{Ethical Considerations}

The WMA Declaration of Helsinki (2013) and the ethical procedures required by the university were followed, and the research was approved by the ethical board. Each student was informed about the aim 
of the study, that participation was voluntary and that their identity would not be revealed. All students signed a letter of consent giving permission to record and for research purposes review and analyse the tapes and publish the results. The supervising teachers provided the researcher with the recordings, which have only been viewed by the researcher and will be kept safe, until destroyed.

\section{Data Analyses}

The data analysis was based on a pre-understanding of clinical competence (Lejonqvist et al. 2011) and performed according to the hermeneutical method inspired by Gadamer (1996) with a hypotheticodeductive approach (Føllesdahl 1994). The first hermeneutical circle started from a holistic, inductive and intuitive vision of the scenarios identifying the whole story. The second circle, the hypotheticodeductive circle moved through the deductive categories; encountering, knowing, performing, developing and maturing, placing the forms and expressions of clinical competence in them. After placing the parts, the whole scenario was returned to in order to check the logic and meaningfulness of the categorisation. In the third subject-objective circle the new pre-understanding, the scenarios and actions were combined and in a final interpretation where three basic plots of the story were created.

During the analysis process, notes of each scenario were made but instead of transcribing the observations verbatim, the recording was observed several times to identify and describe the scenarios, the actors and the plot. Each situation represented a story and in watching the stories again and again, moving from the whole story to the parts and back to the whole again, the different categories of clinical competence became visible. Putting words to observations is crucial, and this happened in a dialogue between the pre-understanding and the observations. The observations were based on the roles of the actors, the scenario, what was said and done, why it was said and done, and what the atmosphere was during the situation. The analyses of the tape were done by one researcher (GB), but the transcribed notes as the interpretation of the results were verified by the other researchers (KE and RM).

\section{The Scenarios}

In this simulation a problem and process-based method was used, which placed focus on the learning process and viewed the students as active and information seeking. The students acted based on continuous assessment of the patient to meet the caring needs. The scenarios and objectives developed by the teachers reflected a realistic clinical practise, which began with a brief report of the clinical status of the patient. The scenarios developed in response to student interventions, and the high-fidelity simulator was programmed to trend the scenarios. Findings that could not be simulated were recorded as blood glucose, temperature and sweating, and level of consciousness.

Five different scenarios were simulated: 1) man, age 53 suffering from pneumonia and asthma with deteriorating breathing problems; 2 ) woman, age 83 suffering from coronary disease, diabetes and hypertonia complaining of chest pains and nausea; 3) man, age 56 heavy drinker suffering from diabetes and pancreatitis, vomiting and needing a nasogastric tube; 4 ) man, age 76 suffering from COPD, diabetes, hanging left corner of the mouth, left arm without strength and difficulties in speaking, and 5) man, age 66 having gone through a knee operation, unable to urinate, suffering from stomach pain and pain in the knee.

\section{The Stage, the Actors and the Plot}

The stage was a patient room. The patient, a high-fidelity mannequin operated by two teachers, was in bed surrounded by monitors and equipment. As in a play, the students had to wait their turn, enter the stage (simulation centre), play their role after a designed script dressed in a costume (nursing uniform) whilst being watched and getting feedback from an audience. The students identified with the roles which influenced their performance and made them who they were (Taylor 2014). The patient provided the students with information about his/ her health both verbally and by vital signs. The students performed based on their knowledge, their observations, assessment and the information from the patient. They were alone in the situation but could consult a "doctor" if needed.

The actors were the patient (teachers) and the students. The role as the leading actor differed in the different situations, sometimes being the patient, but more often one of the students depending on experience, clinical competence and confidence.

\section{Results}

\section{The Forms and Expressions of Clinical Competence}

Based on the pre-understanding, all the deductive categories defining clinical competence became evident in the simulated situations. The overall story that could be found when viewing the scenarios was "the way from suffering to health". Clinical competence was formed and expressed differently depending on the situations and the performance of the students. The clinical competence demonstrated appeared in dialectic patterns showing good clinical competence and lack of it. The forms and expressions of competence are shown in Table 1 below.

In the simulated situations the students performed in a role. The performance depended on how confident and how comfortable they were in the situation. Based on their knowledge and skills, they managed the situation by actively participating, volunteering and wanting to perform nursing and caring activities. They managed the equipment and procedures, worked together with the other/s, consulted and delegated. In encountering the patient, they were present, they showed interest, listened to the patient and acted according to the patient's problems and needs in wanting the best for the patient. Maturing and development were least seen in single scenarios but showed in the students' asking questions, sharing knowledge, verifying with peers, consulting and suggesting actions. They foresaw and prepared based on observations, knowledge, and learning from the situation.

All the main categories, the forms and expressions of competence also had their negative counterparts, where students were uninterested, passive, withdrawing, isolated and uncomfortable depending on lack of knowledge, skills or self-confidence.

In the hermeneutical interpretation of the way from suffering to health, three basic plots were found: 1 ) doing as performing and knowing. The students were working evidence-based and responsibly, managing technology and skills, feeling confident and comfortable sharing information and working together with others; 2 ) being as encountering. The students were present, interested in and confirming the patient by listening and responding, and 3 ) becoming as maturing and developing. The students were co-acting and learning together and developing. All students were engaged to some extent in doing according to their own skills; most of them also were being there for the patient whilst fewer could be seen in the process of becoming by developing and maturing in these single scenarios.

\section{Facilitating Development of Clinical Competence in Simulation}

Development of clinical competence was seen from the first to the last case performance during one day. Watching others simulate and participate in debriefings made the activities of the students clearer and safer, and probably affected the performances later during the day even if the scenarios changed. Being aware of each student's knowledge and skills, the teachers designed the scenario. The teachers facilitated the situations, and depending on their performance the students were challenged to develop their individual clinical competence. On the students' way to clinical competence, the teachers were simplifying or 
Table 1

Evidence of clinical competence in simulated situations.

\begin{tabular}{|c|c|c|}
\hline Deductive categories of clinical competence & Shapes of clinical competence & Expressions of clinical competence \\
\hline \multirow[t]{4}{*}{ Encountering/Not encountering } & Confirming & $\begin{array}{l}\text { Greeting the patient by name, touching, meeting the patients eyes, listening, } \\
\text { answering and believing the patient }\end{array}$ \\
\hline & Ignoring & $\begin{array}{l}\text { Talking over the patients head, not listening, not answering, talking to the patient } \\
\text { in a disparaging way }\end{array}$ \\
\hline & Showing interest & Listens to the patients story, asks questions, fulfils wishes \\
\hline & Uninterested & Does not listen to the patient, asks no questions, "drives his/her own race" \\
\hline \multirow[t]{6}{*}{ Knowing/Not knowing } & Being responsible/ & Knows own limitations, asks for help, consults, and checks \\
\hline & Un-responsible & Acts without knowing, does not work aseptically, does not check medication \\
\hline & Acting evidence-based & $\begin{array}{l}\text { Bases actions on knowledge, informs co-workers and the patients, interprets vital } \\
\text { signs and acts based on them, can foresee what is going to happen and prepares }\end{array}$ \\
\hline & Not evidence-based & $\begin{array}{l}\text { Acts on routine, gives no information or explanations to actions, does not answer } \\
\text { questions, cannot foresee course of events, works unsystematically and unorganised }\end{array}$ \\
\hline & Knowing technology and techniques & Manages equipment and procedures \\
\hline & Technology and techniques unknown & Needs help from other students, makes mistakes and endangers patient safety \\
\hline \multirow[t]{6}{*}{$\begin{array}{l}\text { Performing/ } \\
\text { Not performing }\end{array}$} & Acting confident & $\begin{array}{l}\text { Knows what to do, acts consequently, interacts with the patient and other students, } \\
\text { knows manual skills, has good routines }\end{array}$ \\
\hline & Not confident & $\begin{array}{l}\text { Does not know what to do, waits for order, does not acknowledge the patient, little } \\
\text { interaction, uncertain about manual skills, works unsystematically }\end{array}$ \\
\hline & Feeling comfortable/ & Enjoys the situation, acts naturally \\
\hline & Uncomfortable & Nervous, does not engage in the situation, laughs and acts un-naturally \\
\hline & Being connective and sharing & Team-work abilities, informs, delegates, gives suggestions, supports and confirm \\
\hline & “Loner” & $\begin{array}{l}\text { Prefers working alone, does not share information, does not delegate, picks tasks, } \\
\text { withdraws from the group/other }\end{array}$ \\
\hline \multirow[t]{2}{*}{$\begin{array}{l}\text { Maturing, developing/not maturing, } \\
\text { not developing }\end{array}$} & Learning & $\begin{array}{l}\text { Taking advice, asking questions, discussing alternatives and giving suggestions, } \\
\text { active and willing to do }\end{array}$ \\
\hline & Stagnation & Being passive, waiting for other/s initiative, unwilling to act \\
\hline
\end{tabular}

complicating the scenarios, giving or withholding information, and continuing or ending the situation thus enabling learning to take place. The scenario was facilitated by adding more challenging symptoms and signs, thus trusting the students to manage the situation, or it was made simpler and easier to manage by giving additional instructions and information about the patient.

The "case" was continued until the students were using their whole potential and learning new things, thus developing their clinical competence. The "case" was ended when the students could not manage it any more in order to avoid the feeling of failure.

\section{Discussion}

Using a hermeneutic method with a hypothetic-deductive approach to observations of simulated situations is challenging. However the results of this study show that simulation offers safe training of skills, problem solving, critical thinking, decision making, communication, and group- and teamwork, which are well in line with earlier research (Robinson-Smith et al. 2009, Burns et al. 2010, Alfes 2011, Garrett et al. 2011). We also found that, in well-designed simulation training, evidence of clinical competence as encountering, knowing, performing, maturing, and developing can be made visible in different simulated contexts, and thereby trained. We also found that a few students did not feel comfortable or confident in the situation, which was revealed as ignoring the patient, being uninterested and not responsible, or as withdrawing from the situation. Simulation training requires not only that students identify with their roles, and allow themselves to be influenced, taking the play as "reality" (Gadamer 1996), but also that they have the knowledge and skills needed in the situation, since they need to feel safe and be prepared. Simulation can be seen as a play, a performance, but even so it holds all the elements and possibilities needed to evaluate and develop clinical competence, and as such is a valuable teaching and learning method in nursing education. The challenge lies in encountering the suffering of the patient (McCaughey \& Traynor 2010, Berragan 2011, McGarry et al. 2014) with compassion, walking with the patient, and that is where the ethics of caring and the caring abilities really show (Eriksson 2006). This implies reaching the level where the play no longer exists but only the meaning (Gadamer 1996).
In simulated situations, students develop not only their manual clinical skills but also their team-work competence, their reporting and consulting, and they gain reinforcement in their learning processes both from teachers and from fellow students. In simulations, the students have the possibilities to repeat and to watch others and their own performances, and the awareness of knowledge gaps becomes obvious, which in turn leads to learning activities. The teachers facilitate learning by simplifying or complicating the situation of the patient by designing scenes according to the level of the clinical competence of each student, which can challenge them to do their very best and in that way develop clinical competence. This requires trust, time, space and equipment, small student groups and well-trained teachers, which provides an effective, although expensive, way to learn and teach.

In this study of clinical competence, performing became most evident. This compares well with what is evaluated in both simulation and practical training (While 1994, Berragan 2014).

Simulation can be used to evaluate clinical competence, and when there is a lack of good and varying clinical training places, simulation is a good alternative. It can be used to check students' clinical competence before graduation and offer possibilities to develop it if needed. Although simulation is the best alternative, it cannot replace practical training. However, simulation can make the transition from theory to clinical practise easier as it gives students the possibilities to train safely and to develop the self-confidence they need in practise, even if it is never the same as practise.

\section{Limitations}

The limitation of the study lies in its transferability due to the small sample size and the context of one specific university. Still, the richness in the findings and the similarity to other research results support its validity. The researcher's pre-understanding (Lejonqvist et al. 2011), familiarity with simulation teaching, the students' curriculum and the simulation centre were used in interpreting the situations. This can be seen both as a strength and as a weakness, but, as Gadamer (1996) states, prejudices are important in the interpretation, since they form the basis for understanding. This study also supported the results in the above-mentioned study in defining clinical competence, but at the 
same time it illuminates the correlation between competence and performance.

\section{Conclusions}

Based on our pre-understanding, our study showed that simulation learning is a good way to demonstrate and develop all aspects of a clinical competence and that the challenge lies in truly encountering the patient. Simulation is a valuable complement to other forms of learning. To succeed in this, students need to come to the simulations prepared, and they need to study by themselves. In simulations, students can show a wide range of knowledge, skills and competence. Evidence of clinical competence is more than performing though - it is expressing motives for performance and explaining it, it is revising performance based on knowledge, co-operation and observations of the patient. This study shows that in simulation all these aspects are present.

\section{References}

Alfes, C.M., 2011. Evaluating the use of simulation with beginning nursing students. J. Nurs. Educ. 50 (2), 89-93.

Avis, M., Freshwater, D., 2006. Evidence for practice, epistemology, and critical reflection. Nurs. Philos. 7 (4), 216-224.

Berragan, L., 2011. Simulation: an effective pedagogical approach for nursing. Nurse Educ. Today 31 (7), 660-663.

Berragan, L., 2014. Learning nursing through simulation: a case study approach towards an expansive model of learning. Nurse Educ. Today 34 (8), 1143-1148.

Burns, H., O'Donnell, J., Artman, J., 2010. High-fidelity simulation in teaching problem solving to 1st-year nursing students: a novel use of the nursing process. Clin. Simul. Nurs. 6 (3), 87-95. http://dx.doi.org/10.1016/j.ecns.2009.07.005.

Cant, R.P., Cooper, S.J., 2010. Simulation-based learning in nurse education: systematic review. J. Adv. Nurs. 66 (1), 3-15.

Cassidy, S., 2009. Interpretation of competence in student assessment. Nurs. Stand. 23 (18), 39-45.

Cook, D., Hamstra, S., Brydges, R., Zendejas, B., Szostek, J., Wang, A., Erwin, R., Hatala, R. 2013. Comparative effectiveness of instructional design features in simulationbased education: systematic review and meta-analysis. Med. Teach. 35 (1), 867-898. http://dx.doi.org/10.3109/0142159X.2012.714886.

Eriksson, K., 2006. The Suffering Human Being. ABC Printing Company, Chicago.

Eriksson, K., 2010. Evidence: to see or not to see. Nurs. Sci. Q. 23 (4), 275-279.

Eriksson, T., Lindahl, B., Bergbom, I., 2010. Visits in an intensive care unit-an observational hermeneutic study. Intensive crit. Care Nurs. 26 (1), 51-57.

Føllesdal, D., 1994. Hermeneutics and the Hypothetico-Deductive Method. Martin, M. \& McIntyre, L. Readings in the philosophy of social sciences. Cambridge, MIT Press, In.

Gadamer, H.G., 1996. Truth and Method. second ed. London, Sheed \& Ward Ltd.

Gallo, K., Smith, L., 2014. Building a Culture of Patient Safety Through Simulation SKU\# 9780826169068

Garrett, B., MacPhee, M., Jackson, C., 2011. Implementing high-fidelity simulation in Canada: reflections on 3 years of practice. Nurse Educ. Today 3 (7), 671-676.

Gordon, C.J., Buckley, T., 2009. The effect of high-fidelity simulation training on medicalsurgical graduate nurses' perceived ability to respond to patient clinical emergencies. J. Contin. Educ. Nurs. 40 (11), 491-498.

Hinchcliffe, D.N., 2014. Simulation education: a primer for professionalism. Teach. Learn. Nurs. 9 (3), 126-129.

Ironside, P.M., Jeffries, P.R., Martin, A., 2009. Fostering patient safety competencies using multiple-patient simulation experiences. Nurs. Outlook 57 (6), 7-332.

Jensen, R., 2012. Clinical reasoning during simulation: comparison of student and faculty ratings. Nurse Educ. Pract. 13 (1), 23-28.

Kameg, K., Howard, V.M., Clochesy, J., Mitchell, A.M., Suresky, J.M., 2010. The impact of high fidelity human simulation on self-efficacy of communication skills. Issues Ment. Health Nurs. 31 (5), 315-323.

Kaplan, B., Ura, D., 2010. Use of multiple patient simulators to enhance prioritizing and delegating skills for senior nursing students. J. Nurs. Educ. 49 (7), 371-377.

Khalaila, R., 2014. Simulation in nursing education: an evaluation of students' outcomes at their first clinical practice combined with simulations. Nurse Educ. Today 34 (2), 252-258.

Kolb, A., Kolb, D., 2005. Learning styles and learning spaces: enhancing experiential learning in higher education. Acad. Manag. Learn. Educ. 4 (2), 193-212. http://dx.doi.org/ 10.5465/AMLE.2005.17268566.

Lejonqvist, G.-B., Eriksson, K., Meretoja, R., 2011. Evidence of clinical competence. Scand. J. Caring Sci. 26 (2), 340-348.

Levett-Jones, T., Lapkin, S., 2014. A systematic review of the effectiveness of simulation debriefing in health professional education. Nurse Educ. Today 34 (6), 58-63.
Lyons, J., 2012. Learning with technology: theoretical foundations underpinning simulations in higher education. In: Brown, M., Harnett, M., Stewart, T. (Eds.), Future Challenges, Sustainable Futures. Proceedings Ascilite Wellington, pp. 582-586.

McCallum, J., 2007. The debate in favour of using simulation education in pre-registration adult nursing. Nurse Educ. Today 27 (8), 825-831.

McCaughey, C.S., Traynor, M.K., 2010. The role of simulation in nurse education. Nurse Educ. Today 30 (8), 827-832.

McGarry, D., Cashin, A., Fowler, C., 2014. Is high fidelity human patient (mannequin) simulation, simulation of learning? Nurse Educ. Today 34 (8), 1138-1142. http://dx.doi. org/10.1016/j.nedt.2014.04.014.

McGarth, M., Lyng, C., Hourican, S., 2012. From the simulation lab to the ward: preparing 4th year nursing students for the role of staff nurse. Clin. Simul. Nurs. 8 (7), 265-272 (http://www.nursingsimulation.org/article/S1876-1399(10)00189-1/abstract. Last accessed 11.32014$)$.

Meretoja, R., Isoaho, H., Leino-Kilpi, H., 2004. Nurse competence scale: development and psychometric testing. J. Adv. Nurs. 47 (2), 124-133.

Murphy, S., Hartigan, J., Walsh, N., Flynn, A., O'Brien, S., 2011. Merging problem-based learning and simulation as an innovative pedagogy in nurse education. Clin. Simul. Nurs. 7 (4), e141-e148.

Nehring, W.M., Lashley, F.R., 2009. Nursing simulation: a review of the past 40 years. Simul. Gambl. 40 (4), 528-552. http://dx.doi.org/10.1177/1046878109332282.

Ödman, P.-J., 1979. Tolkning, Förståelse och Vetande. Hermeneutik i Teori och Praktik. (Transl. Interpretation, Understanding and Knowing. Hermeneutics in Theory and Practice.). AWE/Geber, Halmstad.

Pearson, E., McLafferty, I., 2011. The use of simulation as a learning approach to nontechnical skills awareness in final year students. Nurse Educ. Pract. 11 (6), 399-405.

Reid-Searl, K., Happell, B., Vieth, L., Eaton, A., 2012. High fidelity patient silicone simulation: a qualitative evaluation of nursing students' experiences. Collegian 19 (2), 77-83.

Roberts, T., Vignato, J., Moore, J., Madden, C., 2009. Promoting skill building and confidence in freshman nursing students with a "skills-a-thon". J. Nurs. Educ. 48 (8), 460-464.

Robinson-Smith, G., Bradley, P.K., Meakin, C., 2009. Evaluating the use of standardized patients in undergraduate psychiatric nursing experiences. Clin. Simul. Nurs. 5 (6), 203-211 (http://www.nursingsimulation.org/article/S1876-1399(09)00499-X/abstract. Last accessed 11.3.2014).

Rochester, S., Kelly, M., Disler, R., White, H., Forber, J., Matiuk, S., 2012. Providing simulation experiences for large cohorts of 1 st year nursing students: evaluating quality and impact. Collegian. Aust. J. Nurs. Pract., Scholarsh. Res. 19 (3), 117-124.

Schmidt, H., Rotgans, J., Yew, E., 2011. The process of problem-based learning: what works and why. Med. Educ. 45 (8), 792-806. http://dx.doi.org/10.1111/j.13652923.2011.04035.x. PMID 21752076.

Scott, K., McSherry, R., 2008. Evidence-based nursing: clarifying the concepts for nurses in practice. J. Clin. Nurs. 18 (8), 1085-1095.

Skrable, L., Fitzsimons, V., 2014. Simulation in associate degree nursing education: a literature review. Teach. Learn. Nurs. 9 (3), 120-125.

Smith, S., 2012. Nurse competence: a concept analysis. Int. J. Nurs. Knowledge 23 (3), 172-182.

Solnick, A., Weiss, S., 2007. High fidelity simulation in nursing education: a review of the literature. Clin. Simul. Nurs. Educ. 3 (1), 41-45 (http://www.nursingsimulation.org/ article/S1876-1399(09)00470-8/abstract. Last accessed 11.3.2014).

Stanford, P., 2010. Simulation in nursing education: a review of the research. Qual. Rep. 15 (4), 1006-1011 (http://www.nova.edu/ssss/QR/QR15-4/stanford.pdf. Last accessed 11.3.2014).

Taylor, N., 2014. We're play-acting: simulation and dramaturgical sociology. Clin. Simul. Nurs. 10 (11), 554-558. http://dx.doi.org/10.1016/j.ecns.2014.08.004.

The WMA, 2013. Declaration of Helsinki-Ethical Principles for Medical Research Involving Human Subjects. http://www.wma.net/en/30publications/10policies/b3/ (Last accessed 11.3.2014).

Thomas, C., Mackey, E., 2012. Influence of a clinical simulation elective on baccalaureate nursing student clinical confidence. J. Nurs. Educ. 51 (4), 236-239. http://dx.doi. org/10.3928/01484834-20120224-03.

Tilley, D.D.S., 2008. Competency in nursing: a concept analysis. J. Contin. Educ. Nurs. 39 (2), 58-66.

Tosterud, R., Hedelin, B., Hall-Lord, M.L., 2013. Nursing students' perceptions of high- and low-fidelity simulation used as learning methods. Nurse Educ. Pract 13 (4), 262-270.

While, A., 1994. Competence versus performance: which is more important? J. Adv. Nurs. 20 (3), 525-531.

White, A., Brannan, J., Long, J., Kruszka, K., 2013. Comparison of instructional methods: Cognitive skills and confidence levels. Clin. Simul. Nurs. 9, 417-423.

WHO, 2004. First Do No Harm. World Alliance for Patient Safety, Washington (http:// www.who.int/patientsafety/worldalliance/en/. Last accessed 16.12.2014).

Yeun, E., Bang, H., Ryoo, E., Ha, E.-H., 2014. Attitudes toward simulation-based learning in nursing students: an application of Q methodology. Nurse Educ. Today 34 (7), 1062-1068. http://dx.doi.org/10.1016/j.nedt.2014.02.008.

Yuan, H.B., Williams, B.A., Fang, J.B., 2011. The contribution of high-fidelity simulation to nursing students' confidence and competence: a systematic review. Int. Nurs. Rev. 59 (1), 26-33. 